\title{
Analysis on the Issues and Current Situation of Software Project Management in China
}

\author{
Shuangxi Zhang*
}

Institute of Graduate School, SEGi University, Kota Damansara 47810, Petaling Jaya, Selangor, Malaysia. E-mail: zsx554201@hotmail.com

Abstract: This paper innovatively applies the methods of bibliometric and content analysis to analyze the journals in the field of software project management. It studies the overall development trend of software project management and the evolution of research hot topics from the quantitative trend and content trend, and obtains the development trend of relevant journals from 2001 to 2019. In view of this research problem, from the number of journals published, the corresponding analysis and statistics of relevant contents, the paper analyzes the development issues and the current situation of software project management in China from 2001 to 2019.

Keywords: Software Project Management; Development Issues; Current Situation Bibliometric Method

\section{Introduction}

In the 1970s and 1980s, the software industry grew very quickly. Software project management has been widely concerned. Software project management and software development technology are regarded as countermeasures to eliminate "software crisis". Compared with other industries with relevant complete project management theory, the development and practice of software project management theory is still in the stage of exploration and development. While text mining technology has been applied in many fields of project management, but most of them focus on the risk management and decision-making management of project management in China. For the field of software project management, no scholars have done relevant research. Based on this, in order to explore the development status of China's software projects, this paper will combine the text mining technology with the literature measurement method and content analysis method to analyze the rele- vant literature of the journal database based on CNKI.

\section{Research question}

This paper proposes one research question pertaining to software project management: how to get the main issues and current situation of China's software project management through literature analysis?

The aim of this study is to find out the issues and the current situation of software project management in China through literature analysis. It also points out the direction for future research.

\section{Methodology}

The bibliometric method mainly uses mathematical and statistical methods to express the basic laws in the process of document information exchange with mathematical models ${ }^{[1]}$. This paper selects CNKI journal retrieval system. Based on the keywords of "software project management and current situation” are formulated, 
the retrieval time is the whole time, the retrieval expression is "software project" and "current situation", the type of literature is the core journal, China is the region of retrieval strategy, and the data of all journals that are about software project are retrieved. After optimizing the retrieval strategy, 357 papers were retrieved again. Through reading these articles, 90 papers that relate to this paper were selected. From these 90 papers, to summarize the issues and current situation of software project management in China mentioned in each paper, which is sorted out the problem statements. BIBEXCEL is used to analyze the problem statements that mentioned in 90 articles to get the co-occurrence matrix. According to data, PAJEK, CITESPACE and VOSVIEWER are used to visualize the co-occurrence matrix. After merging similar problem statements, frequency analysis is carried out on the data after reorganizing via SPSS.

\section{Data analysis and results}

By reading these 90 journals, there are 28 problem statements that are numbered from a to $\mathrm{z}, \mathrm{z} 1$ and $\mathrm{z} 2$, then are sorted and combined into six problem statements, which are numbered A to $\mathrm{F}$.

A. "Lack of understanding of software project development management” includes: lack of understanding of software project development management; Theory can't keep up with the times; lack of project management system training; lack of project management professionals; and technology over management.

B. "Insufficient systematic grasp of the project" includes: unrealistic expectations; poor control over the project; insufficient systematic grasp of the project; development out of document; the standardization of software project management is not high; there is a problem with the development mode, technology or auxiliary management tools selected for the software project; project scope control; project planning issues ${ }^{[2]}$; and aware- ness of project planning.

C. "Lack of management awareness ${ }^{[3] "}$ includes: backward management platform; large turnover of management personnel; imperfect management system; the current situation of organizational structure of IT enterprises in China; and lack of management awareness $^{[4]}$.

D. "Lack of awareness of project risk management" includes: lack of awareness of project risk management ${ }^{[5]}$; the restriction of software product quality factors; low success rate of software projects; and the project team's ability to deal with emergencies is limited.

E. "Lack of effective communication" includes: lack of effective communication ${ }^{[6]}$; issues related to project stakeholders ${ }^{[7]}$; division of labor and cooperation within the project team ${ }^{[8]}$; and demand management issues.

F: "Lack of summary of project experience" includes lack of summary of project experience.

\subsection{Analysis on development stage}

Table 1 shows the number of journals published each year from 2001 to 2019. There are a total of 90 Chinese journals. It can be seen from the broken line chart shown in the Table 1 that from 2001 to 2004, the research on the current situation of software project management was basically in a blank period; from 2005 to 2008, the study on the issues and current situation of software project management was in a rapid development stage; from 2009 to 2015, it was in a fluctuating development stage, and the overall trend did not show an upward trend. This phenomenon shows that during this period, the research hot topics of software project management were some Changes: from 2016 to 2017, there was the obvious upward trend; However, from 2018, due to the incomplete storage of CNKI Journals, the statistics have declined.

\begin{tabular}{|c|c|c|c|c|c|c|c|c|c|c|c|c|c|c|c|c|c|c|c|}
\hline Number & 产 & 芯 & 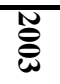 & 产 & 范 & 产 & స్త్ర & No & ్ㅡㅇ & 苍 & $\stackrel{N}{\mathscr{O}}$ & $\stackrel{N}{\stackrel{N}{N}}$ & $\stackrel{\widetilde{O}}{\tilde{\omega}}$ & 莒 & 苍 & $\begin{array}{l}\tilde{O} \\
\sigma\end{array}$ & $\stackrel{\widetilde{O}}{\stackrel{S}{G}}$ & $\underset{\infty}{\stackrel{N}{O}}$ & 苍 \\
\hline Related papers & 1 & & 1 & 1 & 4 & 4 & 6 & 8 & 7 & 6 & 8 & 5 & 8 & 7 & 2 & 7 & 11 & 3 & 1 \\
\hline Total & 3 & 2 & 11 & 8 & 19 & 18 & 23 & 32 & 19 & 27 & 24 & 25 & 33 & 30 & 25 & 23 & 14 & 9 & 11 \\
\hline
\end{tabular}

Table 1. Quantity of Literature from 2001 to 2019

\subsection{Research focus and evolution analysis}

28 problem statements are analyzed with BIBEX$\mathrm{CEL}^{[9]}$, and the $28 * 28$ order co-occurrence matrix is fi- nally generated. PAJEK, CITESPACE and VOSVIEWER are used to visualize the co-occurrence matrix.

The following phenomena can be found through the 


\section{Figure 1.}

"Lack of effective communication”, "Issues related to project stakeholders", "Lack of awareness of project risk management”, "Backward management platform” and "Poor control over the project" are mentioned more frequently, and are also the five problem statements that have been studied more.

"Lack of summary of project experience” (cluster F), it's a relatively isolated problem, which has little relevance to other problem statements. Cluster E, cluster D and cluster B are more related to each other, cluster A and cluster $\mathrm{C}$ are less, and cluster $\mathrm{f}$ is the least.

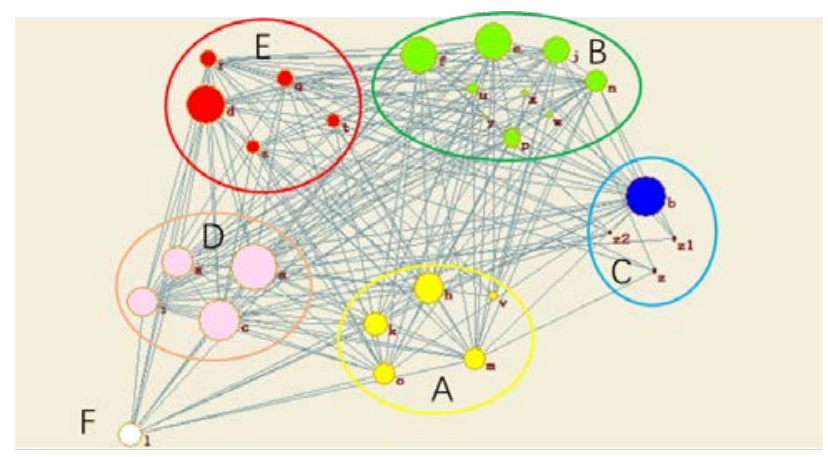

Figure 1. Cluster Network of Problem Statements.

The following phenomena can be found through the

\section{Figure 1.}

“Lack of summary of project experience” (cluster F), it's a relatively isolated issue, which has little relevance to other problem statements.

Cluster E, cluster D and cluster B are more related to each other, cluster $\mathrm{A}$ and cluster $\mathrm{C}$ are less, and cluster $\mathrm{F}$ is the least.

Figure 1 clearly shows that code a, b, c, d, e and $\mathrm{f}$ are research hot topics. They are: "Lack of effective communication", "Lack of awareness of project risk management”, "Issues related to project stakeholders”, "Backward management platform", "Poor control over the project" and "Insufficient systematic grasp of the project”.

Via CITESPACE analysis, in recent years, the hot topics of research are as follows: “Theory can't keep up with the times”, “The project team's ability to deal with emergencies is limited", "Poor control over the project", "The restriction of software product quality factors" and "There is a problem with the development mode, technology or auxiliary management tools selected for the software project”.

\subsection{Frequency analysis}

Analyzing via SPSS, the following results are obtained, as shown in Table 2.

\begin{tabular}{|c|c|c|c|c|c|}
\hline Problem Statements & & Frequency & Percent & $\begin{array}{c}\text { Valid } \\
\text { Percent }\end{array}$ & $\begin{array}{c}\text { Cumulative } \\
\text { Percent }\end{array}$ \\
\hline \multirow[t]{3}{*}{ Lack of understanding of software project development management } & NO & 29 & 32.2 & 32.2 & 32.2 \\
\hline & YES & 61 & 67.8 & 67.8 & 100.0 \\
\hline & Total & 90 & 100.0 & 100.0 & \\
\hline \multirow[t]{3}{*}{ Insufficient systematic grasp of the project } & NO & 14 & 15.6 & 15.6 & 15.6 \\
\hline & YES & 76 & 84.4 & 84.4 & 100.0 \\
\hline & Total & 90 & 100.0 & 100.0 & \\
\hline \multirow[t]{3}{*}{ Lack of the consciousness of management } & NO & 34 & 37.8 & 37.8 & 37.8 \\
\hline & YES & 56 & 62.2 & 62.2 & 100.0 \\
\hline & Total & 90 & 100.0 & 100.0 & \\
\hline \multirow[t]{3}{*}{ Lack of awareness of project risk management } & NO & 45 & 50.0 & 50.0 & 50.0 \\
\hline & YES & 45 & 50.0 & 50.0 & 100.0 \\
\hline & Total & 90 & 100.0 & 100.0 & \\
\hline Lack of effective communication mechanism & NO & 11 & 12.2 & 12.2 & 12.2 \\
\hline
\end{tabular}




\begin{tabular}{cccccc}
\hline Problem Statements & & Frequency & Percent & $\begin{array}{c}\text { Valid } \\
\text { Percent }\end{array}$ & $\begin{array}{c}\text { Cumulative } \\
\text { Percent }\end{array}$ \\
\hline & YES & 79 & 87.8 & 87.8 & 100.0 \\
Lack of summary of project experience & Total & 90 & 100.0 & 100.0 & \\
& NO & 75 & 83.3 & 83.3 & 83.3 \\
& YES & 15 & 16.7 & 16.7 & 100.0 \\
& Total & 90 & 100.0 & 100.0 & \\
\hline
\end{tabular}

Table 2. Statistical analysis of Problem Statements

Table 2 shows that the research on "Lack of summary of project experience” is relatively small and pays little attention to it, which is the direction that should be strengthened in the future. "Insufficient systematic grasp of the project" and "Lack of effective communication mechanism" are mentioned more, which also shows that they are more concerned now.

\section{Conclusion}

In summary, the results of text mining analysis based on software project management and problems can be concluded as follows.

In terms of the overall quantity, the literature shows a rapid upward trend after the twists and turns in 2015, which shows that Chinese scholars have a high degree of concern about the problem statements existing in software project management in China. It also shows that Chinese enterprises begin to realize the importance of software project management.

In recent years, the distribution of issues in software project management is mainly as follows: "Poor control over the project”, "Unrealistic expectations”, “The project team's ability to deal with emergencies is limited” and "The restriction of software product quality factors".

In short, through the distribution and analysis of the key issues related to the journals from 2001 to 2019, it can be concluded that there are 6 problem statements in the current software project management, which can be used for reference by scholars in the industry.

\section{References}

1. Liu Q. Application examples of Bibexcel in bibliometric analysis (in Chinese). Journal of Hubei Second Normal University 2011; (8): 83-84.

2. Zhang $X$. Analysis and countermeasures of key problems in software project management (in Chinese). Information System Engineering 2016; 267(3): 130.

3. Xia C. Analysis of computer software project management implementation countermeasures (in Chinese). Computer Products and Circulation 2018; (2): 288.

4. Su L. Current situation of software project management and countermeasure analysis (in Chinese). China's Strategic Emerging Industries 2017; (12X): 101.

5. Yang Z. Analysis and countermeasures of key issues in software project management (in Chinese). Computer Products and Circulation 2017; (9): 40.

6. Jiang C. Talking about the problems and solving strategies in software R\&D project management (in Chinese). Neijiang Science and Technology 2017; 38(8): 5+25.

7. Qi B. Application and improvement of software project management in software development (in Chinese). Computer Products and Circulation 2017; (9): 41.

8. Xin H, Yu H. Application and improvement of software project management in software development (in Chinese). China Strategic Emerging Industries 2017; 20, 106.

9. Chu J, Guo C. The basic principle and EXCEL realization of the co-word analysis method (in Chinese). Information Science 2011; 29(6): 931-934. 